

\title{
SUCCESS FACTORS OF CROWDFUNDING CAMPAIGNS IN MEDICAL RESEARCH: PERCEPTIONS AND REALITY
}

\author{
Anna Aleksina ${ }^{1}$ \\ Department of Finance and Accounting, Stockholm School of Economics in Riga \\ Stanislau Akulenka ${ }^{2}$ \\ Department of Finance and Accounting, Stockholm School of Economics in Riga
}

Ágnes Lublóy ${ }^{3}$

Department of Finance and Accounting, Stockholm School of Economics in Riga and

Department of Finance, Corvinus University of Budapest

June 20, 2019.

A revised version of this paper has been published in Drug Discovery Today:

Anna Aleksina, Stanislau Akulenka, Ágnes Lublóy. (2019). Success factors of crowdfunding campaigns in medical research: perceptions and reality. Drug Discovery Today, 24(7): 14131420. doi: https://doi.org/10.1016/j.drudis.2019.05.012

\footnotetext{
${ }^{1}$ Strēlnieku iela 4a, Rīga LV1010, Latvia, aaleksina@sserida.edu (email)

${ }^{2}$ Strēlnieku iela 4a, Rīga LV1010, Latvia, sakulenka.sseriga.edu (email)

${ }^{3}$ Strēlnieku iela 4a, Riga LV1010, Latvia, +371 67015841 (tel), +37167830249 (fax), agnes.lubloy@sseriga.edu (email) and agnes.lubloy@uni-corvinus.hu
} 


\begin{abstract}
Crowdfunding in medical research is becoming more popular due to the shrinking and increasingly competitive government funding. In order to inform researchers applying for this complementary source of research funding, we investigate the determinants of successful crowdfunding campaigns in medical research. We find that establishing and maintaining professional contacts through social media is of major importance for successful crowdfunding campaigns; an additional tweet or retweet significantly increases the success of crowdfunding campaigns. In contrast to the stated preferences of prospective donors, we document that crowdfunding campaigns might achieve their fundraising goal regardless of the disease characteristics. Scientists thus may ask funding for any kind of project, including therapies for rare diseases and diseases with lower mortality rate.
\end{abstract}

JEL codes: H51, I19, L65, O31

Keywords: crowdfunding, medical research, stated preferences, revealed preferences, disease characteristics 


\section{Introduction}

Healthcare systems play an important role in meeting the health needs of populations; they are crucial to the well-being of individuals and families. Healthcare systems have contributed tremendously to the well-being of nations and to the development of social welfare. Rapid developments in medical research have opened new possibilities in the treatment of human disorders. Over decades, medical innovations resulted in higher life expectancy for citizens and generated enormous economic value for the nations (Murphy \& Topel, 2006). As a result, governments in developed countries are ready to invest heavily in medical research. For example, the USA alone spent $\$ 3.5$ tn on healthcare in 2017 , out of which $\$ 34.2 \mathrm{bn}$ were spent on medical research by the government supported National Institutes of Health (NIH), the largest source of funding for medical research in the world (CMS, 2018; NIH, 2018a).

Despite the crucial role medical innovation plays in the life of individuals and in the well-being of societies, since 2003 available NIH funds have been constantly decreasing in real terms with a 5\% budget cut in 2013 (Kuehn, 2014). The lower amount of inflation-adjusted funds has been coupled with a fierce competition for funding. As a result, the percentage of successfullyfunded medical research projects by NIH decreased from around 33\% in 1997 to around 20\% in 2016 (NIH, 2018b). It is reasonable to assume that the difference in the quality of medical research projects that got funding and those which were next best projects but were not funded, is marginal.

The high competition for government funds and the limited funding from the private sector prompted researchers to look for alternative financing options. One such option is crowdfunding which has gained popularity in various fields, such as technology and art, and enabled campaign initiators to efficiently raise funds from a large number of contributors. Crowdfunding in medical research is becoming more and more widespread among scientists partly due to the general growth of the crowdfunding market and partly due to decreasing funding from government institutions. In medical research, crowdfunding campaigns are usually donation-based; some campaigns nevertheless offer rewards to donors, such as lab Tshirts, signed copies of research papers, meetings with scientists (Hughes, 2012).

The motives for crowdfunding in medical research are diverse. Researchers may turn to crowdfunding as a result of unsuccessful grant application for government funding, for obtaining some additional funding for an ongoing research, for funding an early phase research whose preliminary results serve as a precondition for grant applications or to raise the awareness of the general public about an important healthcare issue.

Considering the positive effect of medical research and innovations on individuals and the society as a whole, more widespread crowdfunding by medical researchers might significantly improve welfare and benefit the economy on the long term. In this study, we investigate the determinants of successful crowdfunding campaigns in medical research, with success being measured by the success rate, the ratio of actual funding raised to the fundraising target. The determinants identified in this research might serve as guidance for designing and implementing successful crowdfunding campaigns in medical research. In particular, we assess the impact of four groups of determinants on the success of medical research crowdfunding campaigns. First, we look at the characteristics of the disease targeted by the crowdfunding campaign. It is reasonable to assume that the crowd is inclined to fund more frequent diseases, diseases which are deadlier, diseases which have severe impact on the quality of life of the patients, and diseases where the need for the new treatment is high. Second, we investigate the peculiarities of the medical research and the potential medical innovation. We hypothesize that 
highly innovative research approaches and proposals resulting in more effective treatment are prioritized by contributors. Third, we assess the impact of organizational details on the success rate to see whether donors consider factors such as the type of organization, the qualification of the researchers and the availability of additional funding. Finally, we investigate the influence of factors describing the design of the crowdfunding campaigns and how researchers communicate with the crowd. Previous literature on crowdfunding in other domains unambiguously delineate the importance of building a network and communicating efficiently with potential donors (Mollick, 2014; Byrnes et al., 2014; Perlstein, 2013; Petitjean, 2018; Vachelard et al., 2016).

This research sheds light on the most important factors influencing the success of crowdfunding campaigns in medical research. To the best of our knowledge, this is the first time in the literature when factors affecting the success of crowdfunding campaigns in medical research are identified in a systematic way. Previous literature on crowdfunding either investigated success factors of campaigns in fields other than medical research such as art, design, fashion, film, music, publishing and technology (Mollick, 2014; Petitjean, 2018); assessed specific aspects of medical crowdfunding campaigns, such as the importance of building an audience (Byrnes et al. 2014); or described cases of successful crowdfunding campaigns in medical research without systematically assessing the factors (Fumagalli \& Gouw, 2015; Dahlhausen et al. 2016; Dragojlovic \& Lynd, 2014; Perlstein 2013). No studies have yet assessed the impact of disease characteristics and the peculiarities of the research setting.

At the same time, this study allows to compare the stated preferences of prospective donors as documented by Dragojlovic and Lynd (2016) with the revealed preferences of campaign funders as identified in this research. Dragojlovic and Lynd (2016) conducted an online survey of potential donors in North America to determine the characteristics of drug development research projects that are most likely to appeal to donors. To enable comparison of stated preferences with actual donation purposes, we incorporate 11 out of the 14 attributes identified by Dragojlovic and Lynd (2016). The attribute-list of Dragojlovic and Lynd (2016) is complemented with a number of additional variables found to influence the success of crowdfunding campaigns in various settings other than medical research.

Dragojlovic and Lynd (2016) report that potential donors are comparatively more inclined to support campaigns that aim to treat common diseases, diseases with early age of onset, projects where the proposed treatment most likely will cure the disease and patients will not have the symptoms anymore. Moreover, potential donors are comparatively also more likely to support non-profit organizations, projects where the university of the lead researcher had an excellent reputation, and where other funding was available. Stated preferences, however, might deviate from revealed preferences. Research in other domains shows that preferences estimated from survey experiments do not consistently overlap with the choices made in the real world. For example, the inconsistency between survey-based choices (stated preference) and actual choices (revealed preference) have been shown when consumers were selecting alternativefuel vehicles (Brownstone, Bunch \& Train 2000); picking organic or cloned milk (Brooks \& Lusk, 2010); or young parents had to decide whether to vaccinate their new born child (Lambooij et al. 2015). Beshears, Choi, Laibson and Madrian (2008) enumerate five factors that increase the likelihood of inconsistency between the agents' interests and observed actions: passive choice, limited personal experience, complexity, third-party marketing, and intertemporal choice. Stated behavioural intentions might be inconsistent predictors of future decisions in medical research crowdfunding as well. By looking at the factors listed by Beshears et al. (2018), stated and revealed donation behaviour might deviate from each other 
due to limited personal experience, complexity, and third-party marketing. Due to limited personal experience with the complex medical peer review process, donors might prefer supporting the scientists they either know personally or professionally or from the media. Scientists and universities with high reputation might also be preferred by donors; their reputation serve as an effective marketing tool. Finally, donors might have acquaintances who suffer from the disease and they are eager to provide financial support for campaigns focusing on the disease of their loved ones.

To preview our results, we find that establishing and maintaining professional contacts through social media is of major importance for successful crowdfunding campaigns; an additional tweet or retweet increases the success rate of crowdfunding campaign by one percentage point. Our results suggest that researchers should carefully consider the platform on which they plan to launch their crowdfunding campaign; platforms with large numbers of users might pay off, even if they are profit-oriented and charge a fee. The fundraising goal should be realistic and attainable; we find empirical evidence that the higher the fundraising goal, the lower the probability of succeeding. Moreover, we report that crowdfunding campaigns might achieve their fundraising goal regardless of the disease characteristics. Scientists thus may ask funding for any kind of project, including therapies for rare diseases, diseases with early age of onset, and diseases with low mortality rate.

At the same time, when comparing the actual donation behaviour documented in this research with the stated preferences of prospective donors as reported by Dragojlovic and Lynd (2016), we find empirical evidence of inconsistency between stated and revealed preferences in crowdfunding. In this research, none of the attributes found influential by Dragojlovic and Lynd (2016) were useful in predicting the success rate of crowdfunding campaigns. Stated charitable attitudes and behaviour alone thus cannot be used to forecast actual donation behaviour in crowdfunding medical research.

\section{Materials and methods}

\subsection{Crowdfunding campaigns}

Data about crowdfunding campaigns in medical research is obtained from www.consano.org and www.experiment.com, two crowdfunding platforms being specialized in funding scientific research. These two platforms were chosen after assessing the content and suitability of the crowdfunding platforms listed by Cadogan (2014) and Dragojlovic and Lynd (2014). The main criteria for inclusion were as follows:

1. The platform is among the largest crowdfunding platforms in the US focusing on scientific (medical) research. The geographical constraint was imposed with the aim of comparing the actual funding behaviour with the stated preferences of potential donors from North America (Dragojlovic and Lynd, 2016).

2. The platform covers a variety of diseases instead of a single one, such as cancer or diabetes.

3. Information about past projects is available.

4. The platform presents sufficient information about the medical research and the research team.

The platform Consano is a non-profit crowdfunding platform devoted to medical research; the researchers can keep any funds raised, even if the target is not met (Consano, 2017a). In total, 
64 projects were initiated on this platform, the amount raised exceeded \$1m (Consano, 2017b). The platform Experiment is profit-oriented, it charges 8\% platform fee (Experiment, 2017a). This latter platform follows the 'all-or-nothing' model; only fully funded projects get the donations. By the end of 2017, 743 projects were funded, and $\$ 7.6 \mathrm{~m}$ were pledged by 40,206 backers (Experiment, 2017b). Neither Consano nor Experiment provide tangible rewards; however, project results are shared either with the general public or with the backers only.

Medical research crowdfunding campaigns from these two platforms were included in the sample if they were closed as of 12 February 2018, the final date of data collection. The final sample includes 109 projects, 81 projects from Experiment and 28 from Consano. This sample size is comparable to those used in several prior studies (e.g., Byrnes et al., 2014; Dragojlovic \& Lynd, 2014; Petitjean, 2018).

\subsection{Factors influencing the success of crowdfunding campaigns}

The success rate of campaigns, defined as the percentage of the target sum raised, is used as a dependent variable. Such a dependent variable allows comparison of crowdfunding campaigns with different funding goals.

Independent variables cover the attributes defined by Dragojlovic and Lynd (2016); those attributes were selected after carefully reviewing the crowdfunding literature and consulting university fundraising experts. From the 14 attributes defined by Dragojlovic and Lynd (2016), two attributes were excluded from this research due to data unavailability: 1) the source of fundraising appeal showing the relationship of the backers with the organization asking for donations, and 2) matching donations showing whether each dollar donated to the campaign is matched with any other contribution. In addition, the subjective attribute of university reputation was replaced by the number of research team members with $\mathrm{PhD}$ degrees serving as a proxy for the prestige and credibility of the crowdfunding team.

Independent variables are divided into four groups: disease characteristics (Table 1, Panel A), peculiarities of the medical research (Table 1, Panel B), organizational details (Table 1, Panel C) and characteristics of communication and design (Table 1, Panel D). The attribute-list of Dragojlovic and Lynd (2016) was complemented with some additional variables (Table 1, Panels A-C). To deal with the diverse dataset, among the disease characteristics we differentiate between campaigns related to humans and animals (Table 1, Panel A), whereas among the medical research characteristics we differentiate between campaigns researching a particular topic and developing a cure for a disease (Table 1, Panel B).

Furthermore, we add several variables describing the design of the crowdfunding campaigns and how researchers communicate with the crowd (Table 1, Panel D): the number of tweets, retweets and comments; number of updates; availability of intermediate research findings; availability of photos and videos; the length of the campaign description; and the crowdfunding platform on which the campaign is running. The inclusion of these predictors, not covered by the survey of Dragojlovic and Lynd (2016), is supported by recent empirical evidence. Previous literature on crowdfunding unambiguously suggests the importance of building a network (Hui, Gerber \& Gergle 2014; Mollick, 2014; Byrnes et al., 2014; Perlstein, 2013; Petitjean, 2018; Vachelard et al., 2016). Having a large online social network and sharing information about crowdfunding campaigns on these networks, such as Facebook and Twitter, increases the probability of reaching potential donors and thus the success of crowdfunding campaigns. In 
the literature, the size of the social network is commonly proxied with the number of Facebook friends and/or with the number of Twitter followers. Both the number of Facebook friends (Mollick, 2014; Byrnes et al., 2014) and the number of tweets and retweets (Byrnes et al., 2014) are found to be positively associated with the success of crowdfunding campaigns; the latter variable is included in our model.

Table 1: Factors influencing the success of crowdfunding campaigns

\begin{tabular}{|c|c|c|}
\hline Variable & Name & Explanation \\
\hline \multicolumn{3}{|c|}{ Panel A: Disease characteristics } \\
\hline Human/Animal & human & Binary variable; 1 if the campaign is about humans, 0 if it is related to \\
\hline Age of onset* & $\begin{array}{l}- \text { age } 5 \\
\text { age } 5 \text { - age } 40 \\
\text { age } 40-\text { age } 50 \\
\text { age } 50-\text { age } 70\end{array}$ & $\begin{array}{l}\text { Age at which most patients acquire symptoms of a disease. Binary } \\
\text { variable; } 1 \text { if the symptoms are typically acquired by age of } 5,40,50 \text { or } \\
70 \text {, respectively, } 0 \text { otherwise. The age of onset below } 5 \text { years is used as a } \\
\text { reference group. }\end{array}$ \\
\hline $\begin{array}{l}\text { Disease } \\
\text { frequency* }\end{array}$ & freq & Disease frequency per 100,000 people. \\
\hline $\begin{array}{l}\text { Impact on quality } \\
\text { of life* }\end{array}$ & quality & $\begin{array}{l}\text { Binary variable; } 1 \text { if the impact of the disease on the quality of life of a } \\
\text { patient is severe, } 0 \text { if moderate. The impact is severe if the disease causes } \\
\text { severe pain and discomfort and prevent patients from living at home due } \\
\text { to their disabilities. The impact is moderate if the disease causes } \\
\text { moderate pain and discomfort, and patients face difficulties in conducting } \\
\text { their daily activities. }\end{array}$ \\
\hline $\begin{array}{l}\text { Need for new } \\
\text { treatments* }\end{array}$ & $\begin{array}{l}\text { treat_low } \\
\text { treat_medium } \\
\text { treat_high }\end{array}$ & $\begin{array}{l}\text { Binary variable; } 1 \text { if the need for new treatments is low, medium, or high, } \\
\text { respectively, } 0 \text { otherwise. The need is high if there are no currently } \\
\text { approved treatments for the disease; medium if a treatment is available, } \\
\text { but only increases the length and/or quality of life by a small amount. The } \\
\text { need is low if a treatment which significantly increases the length and/or } \\
\text { quality of life of patients is available. The reference category is the } \\
\text { medium need for new treatments. }\end{array}$ \\
\hline Mortality rate* & mortality & $\begin{array}{l}\text { Proportion of patients with this disease who die within } 10 \text { years after } \\
\text { receiving the diagnosis. }\end{array}$ \\
\hline \multicolumn{3}{|c|}{ Panel B: Medical research characteristics } \\
\hline Cure/Research & cure & $\begin{array}{l}\text { Binary variable; } 1 \text { if the campaign aims at developing a cure for a } \\
\text { disease, } 0 \text { if it aims at researching the phenomenon. }\end{array}$ \\
\hline Innovation level* & innovation & $\begin{array}{l}\text { Binary variable; } 1 \text { if the innovation level of the proposed medical } \\
\text { research is high, } 0 \text { if it is low. The innovation level is considered as high } \\
\text { if the researchers come up with an innovative approach that has never } \\
\text { been used previously to cure the disease or was used in a very different } \\
\text { context. The innovation level is considered as low if researchers test } \\
\text { approaches from previous medical research on new treatment groups or } \\
\text { medical problems. }\end{array}$ \\
\hline $\begin{array}{l}\text { Effectiveness of } \\
\text { proposed } \\
\text { treatment* }\end{array}$ & effectiveness & $\begin{array}{l}\text { Binary variable; } 1 \text { if the proposed treatment will most likely cure the } \\
\text { disease, } 0 \text { if patients will significantly benefit from the treatment, but the } \\
\text { disease is not cured. }\end{array}$ \\
\hline $\begin{array}{l}\text { Development } \\
\text { stage* }\end{array}$ & $\begin{array}{l}\text { devel_st_early } \\
\text { devel_st_mid } \\
\text { devel_st_late }\end{array}$ & $\begin{array}{l}\text { Binary variable; } 1 \text { if a development stage is early, mid or late, } \\
\text { respectively, } 0 \text { otherwise. In case of developing a cure for a disease, the } \\
\text { development stage is early if the research team tests the effectiveness and } \\
\text { toxicity of a large number of possible drugs in the lab using human cells; } \\
\text { mid if they perform tests on mice; late if the drug is tested on humans. In } \\
\text { case of researching a phenomenon, the development stage is early if } \\
\text { there is only an general idea about experiment to be conducted; mid if the } \\
\text { idea has already been tested and first results are available; late if several } \\
\text { experiments has been conducted, and additional funding is needed to } \\
\text { answer questions which were developed during the experiments. The } \\
\text { reference category is the early development stage. }\end{array}$ \\
\hline Fundraising goal* & funding goal & The fundraising goal of the campaign, in US dollars. \\
\hline
\end{tabular}




\begin{tabular}{|c|c|c|}
\hline \multicolumn{3}{|c|}{ Panel C: Organizational characteristics } \\
\hline $\begin{array}{l}\text { Type of } \\
\text { organization* }\end{array}$ & org & Binary variable; 1 if the organization is for-profit, 0 if it is non-profit. \\
\hline $\begin{array}{l}\text { Number of people } \\
\text { with } \mathrm{PhD}\end{array}$ & phd & Number of people in the research team with a PhD degree. \\
\hline $\begin{array}{l}\text { Availability of } \\
\text { other funding* }\end{array}$ & additional fund & Binary variable; 1 if additional funding is available, 0 otherwise. \\
\hline \multicolumn{3}{|c|}{ Panel D: Communication and design } \\
\hline $\begin{array}{l}\text { Tweets \& } \\
\text { retweets }\end{array}$ & twit & $\begin{array}{l}\text { Number of tweets sharing the campaign from open accounts plus the } \\
\text { number of retweets, excluding repeated tweets from the same account. }\end{array}$ \\
\hline Comments & comments & $\begin{array}{l}\text { Number of comments on the project page, excluding comments posted } \\
\text { after the closing date. }\end{array}$ \\
\hline Photo & photo & Binary variable; 1 if there are photos on the campaign page, 0 otherwise. \\
\hline Video & video & Binary variable; 1 if there is a video on the campaign page, 0 otherwise. \\
\hline Updates & updates & $\begin{array}{l}\text { Number of updates on a project, excluding updates posted after the } \\
\text { closing date. }\end{array}$ \\
\hline $\begin{array}{l}\text { Intermediate } \\
\text { results }\end{array}$ & interim results & Binary variable; 1 , if intermediate results are available, 0 otherwise. \\
\hline Length & length & Length of the campaign description measured by the number of words. \\
\hline Platform & platform & $\begin{array}{l}\text { Binary variable; } 1 \text { if a project was posted on experiment.com, } 0 \text { if it is } \\
\text { from consano.org. }\end{array}$ \\
\hline
\end{tabular}

* Variable adopted from Dragojlovic and Lynd (2016)

Having a large audience is a necessary but not sufficient condition for success; researchers should also communicate efficiently with potential donors, both inside and outside their social network. This efficient communication may take several forms. Empirical evidence shows the importance of comments left by backers on the campaign's website (Berliner \& Kenworthy, 2017; Mollick, 2014; Petitjean, 2018); the necessity of utilizing multimedia tools and adding photos and videos to the campaign (Berliner \& Kenworthy, 2017; Mollick, 2014; Makris, 2015; Petitjean, 2018; Vachelard et al., 2016); and posting regular updates and disclosing intermediate research findings (Mollick, 2014; Xu et al., 2014). Finally, the length of the campaign description as an independent variable is motivated by the research of Moy, Chan and Torgler (2018) who find that excessive amount of information negatively affects the fund raised. All these aspects of communication are captured by variables defined in Table 1, Panel D.

Data was collected manually. Variables were obtained from the descriptions of the crowdfunding campaigns with three exceptions: age of onset, 10-year mortality rate, and disease frequency. Such information was typically not included in the campaign description; these variables were determined from various health databases and journal articles. The final dataset, available upon request from the authors, includes the methodology of data collection, the source of additional information, and the value for each variable. In case of missing data, the mean-substitution approach was employed (Schafer \& Graham, 2002).

\subsection{Regression analysis}

Ordinary Least Squares (OLS) regressions are employed to identify the success factors of medical crowdfunding campaigns. These revealed preferences are then compared with the stated preferences as determined by Dragojlovic and Lynd (2016). In this research, OLS 
regressions are preferred over binary response models such as the logit or the probit models; we exploit the information embedded in the extent of underfunding vs overfunding. The success rate shows a large variability, it ranges from $3 \%$ to $489 \%$ in the dataset - had we focused on the fact whether the funding target was reached, information would have been lost. The regression model is specified as follows:

$$
\text { Success rate }_{i}=\beta_{0}+\sum_{j=1}^{n} \beta_{j} X_{i j},
$$

where $\beta_{0}$ is the intercept and $X_{i j}$ corresponds to independent variable $j$ for campaign $i$. OLS regressions are tested for multicollinearity, variance inflation factor (VIF) test is employed. VIF values range from 1.27 to 3.80 with an average value of 2.01 . VIF values lower than 5 indicate that multicollinearity is not a problem in these regressions (Montgomery, Peck, \& Vining, 2012). Outliers are detected by plotting a scatterplot matrix for four non-binary variables (disease frequency, fundraising goal, tweets\&retweets, and comments). We apply a 95\% winsorization for outliers; extreme values outside the confidence interval of $95 \%(2.5 \%$ from both sides of the distribution) are replaced by the upper and lower $2.5 \%$ percentile values.

In the first model, independent variables enter the regression as shown in Table 1. In the second model, in line with the stated preference survey of Dragojlovic and Lynd (2016) categorical variables are used for fundraising goal, mortality rate and disease frequency.

\section{Results and discussion}

\subsection{Descriptive statistics}

Descriptive statistics of the independent variables are shown in Table 2. For binary variables, the mean value provides information about the proportion of observations having a value of 1 . Descriptive statistics of the categorical variables used in the second model are shown in Table A1, in the Appendix.

Table 2: Descriptive statistics $(\mathrm{N}=109)$

\begin{tabular}{lrrrr}
\hline Variable & Mean & Std. Dev. & Min & Max \\
\hline Panel A: Disease characteristics & & & & \\
\hline human/animal (1 human; 0 animal) & 0.89 & 0.31 & 0.00 & 1 \\
- age 5 & 0.03 & 0.16 & 0.00 & 1 \\
age 5 - age 40 & 0.28 & 0.45 & 0.00 & 1 \\
age 40 - age 50 & 0.05 & 0.21 & 0.00 & 1 \\
age 50 - age 70 & 0.64 & 0.48 & 0.00 & 1 \\
freq (per 100,000 people) & 568.46 & $1,372.21$ & 0.04 & 13,000 \\
freq winsorized (per 100,000 people) & 453.79 & 568.36 & 0.73 & 3,000 \\
quality (1 severe; 0 moderate) & 0.72 & 0.45 & 0.00 & 1 \\
treat_low & 0.26 & 0.44 & 0.00 & 1 \\
treat_medium & 0.56 & 0.50 & 0.00 & 1 \\
treat_high & 0.18 & 0.39 & 0.00 & 1 \\
mortality (10 years, in \%) & 43.45 & 21.09 & 0.00 & 100 \\
\hline
\end{tabular}




\begin{tabular}{lrrrr}
\hline Panel B: Medical research characteristics & & & & \\
cure (1 cure; 0 research) & 0.35 & 0.48 & 0.00 & 1 \\
innovation (1 high; 0 low) & 0.72 & 0.45 & 0.00 & 1 \\
effectiveness (1 cure; 0 benefit) & 0.94 & 0.25 & 0.00 & 1 \\
devel_st_early & 0.78 & 0.42 & 0.00 & 1 \\
devel_st_mid & 0.21 & 0.41 & 0.00 & 1 \\
devel_st_late & 0.01 & 0.10 & 0.00 & 1 \\
funding goal & $19,179.34$ & $96,002.68$ & 350.00 & $1,000,000$ \\
funding goal winsorized & $10,470.63$ & $15,147.36$ & 800.00 & 75,000 \\
\hline Panel C: Organizational characteristics & & & & \\
\hline org (1 for-profit; 0 non-profit) & 0.06 & 0.25 & 0.00 & 1 \\
phd (number of researchers) & 0.72 & 1.02 & 0.00 & 5 \\
additional fund (1 yes; 0 no) & 0.28 & 0.45 & 0.00 & 1 \\
\hline Panel D: Communication and design & & & & \\
\hline twit & 28.27 & 206.64 & 0.00 & 2,155 \\
twit winsorized & 9.38 & 22.30 & 0.00 & 115 \\
comments & 16.84 & 36.81 & 0.00 & 303 \\
comments winsorized & 15.26 & 26.67 & 0.00 & 139 \\
photo & 0.77 & 0.42 & 0.00 & 1 \\
video & 0.64 & 0.48 & 0.00 & 1 \\
updates & 3.78 & 5.65 & 0.00 & 28 \\
interim results & 0.28 & 0.45 & 0.00 & 1 \\
length & 900.92 & 323.20 & 427.00 & 1,706 \\
platform (1 Experiment; 0 Consano) & 0.74 & 0.44 & 0.00 & 1 \\
\hline
\end{tabular}

For the four variables with outliers, figures in italics show the descriptive statistics after winsorization.

\subsection{Regression analysis}

OLS regression results of the first model are shown in Table 3. Similar conclusions can be drawn from the second model (Table A2, Appendix).

Communication plays an important role in launching a successful crowdfunding campaign. The coefficient of the tweets \& retweets (twit winsorized) variable is positive and significant; an additional tweet or retweet increases the success rate of a campaign by 1.79 . The positive and significant effect of the number of tweets on the success of crowdfunding campaigns is in line with previous findings. Perlstein (2013) estimate that in their pharmacological Crowd4Discovery crowdfunding campaign $60 \%$ of the donors were part of his social networks in Facebook and Twitter. At the same time, Byrnes et al. (2014) swon that engagement of a large audience is of major importance to successful crowdfunding in science. In order to engage, scientists first have to build an audience for their research through the press and online social media such as Facebook and Twitter. Once the audience is built and the crowdfunding campaign is on, scientist should maintain the public presence through tweets, e-mails or press releases. As a result of these tweets, e-mails and press appearances, people will view the project page and donate. Vachelard et al. (2016) also argue that the success of the crowdfunding campaign heavily depends on the social network of the fundraisers. They suggest the fundraising team to reach out to their connections before launching the crowdfunding campaign. 
Table 3: OLS regression results

\begin{tabular}{|c|c|c|c|}
\hline Variables & coefficients & p-value & $95 \% \mathrm{CI}$ \\
\hline \multicolumn{4}{|l|}{ Disease characteristics } \\
\hline human/animal & 4.89 & 0.91 & {$[-23.26-26.22]$} \\
\hline age 5 - age 40 & 0.90 & 0.81 & {$[-59.32-75.89]$} \\
\hline age $40-$ age 50 & 18.58 & 0.33 & {$[-100.81-34.14]$} \\
\hline age $50-$ age 70 & $-28.378^{*}$ & 0.93 & {$[-64.65-59.4]$} \\
\hline freq winsorized & 0.01 & 0.50 & {$[-0.01-0.02]$} \\
\hline quality & 24.60 & 0.13 & {$[-8.2-61.33]$} \\
\hline treat_low & 24.99 & 0.08 & {$[-2.78-51.59]$} \\
\hline treat_high & 20.35 & 0.17 & {$[-11.43-64.98]$} \\
\hline mortality (10 years) & 0.16 & 0.44 & {$[-0.25-0.58]$} \\
\hline \multicolumn{4}{|l|}{$\begin{array}{l}\text { Medical research } \\
\text { characteristics }\end{array}$} \\
\hline cure & 3.13 & 0.75 & {$[-16.17-22.42]$} \\
\hline innovation & $-20.12 *$ & 0.03 & {$[-38.45--1.8]$} \\
\hline effectiveness & 7.58 & 0.55 & {$[-17.45-32.61]$} \\
\hline devel_st_mid & 13.12 & 0.35 & {$[-14.62-40.86]$} \\
\hline devel_st_late & -17.62 & 0.30 & {$[-50.87-15.62]$} \\
\hline funding goal winsorized & $-0.0008^{*}$ & 0.04 & {$[-0.0016-0.0000]$} \\
\hline \multicolumn{4}{|c|}{ Organizational characteristics } \\
\hline org & -26.79 & 0.33 & {$[-81.18-27.6]$} \\
\hline phd & 5.56 & 0.33 & {$[-5.77-16.89]$} \\
\hline additional fund & 2.37 & 0.83 & {$[-19.23-23.97]$} \\
\hline \multicolumn{4}{|c|}{ Communication and design } \\
\hline length & -0.01 & 0.44 & {$[-0.03-0.01]$} \\
\hline comments winsorized & -0.56 & 0.07 & {$[-1.17-0.04]$} \\
\hline twit winsorized & $1.79 * * *$ & 0.00 & {$[0.84-2.75]$} \\
\hline photo & -14.06 & 0.18 & {$[-34.69-6.57]$} \\
\hline video & 7.31 & 0.51 & {$[-14.51-29.13]$} \\
\hline updates & 1.43 & 0.19 & {$[-0.71-3.57]$} \\
\hline results & -3.90 & 0.72 & {$[-25.02-17.23]$} \\
\hline platform & $38.86 *$ & 0.01 & {$[9.46-68.27]$} \\
\hline
\end{tabular}

Coefficients that are significant at least at the 5\% level are highlighted in bold. The R-squared of the model is 0.5873 , while the adjusted R-squared is 0.4565 .

Our results suggest that fundraisers should select the crowdfunding platform carefully. If a campaign is launched on Experiment, the success rate of the campaign is by 38.86 and 48.80 percentage points higher as compared to launching the campaign on Consano. On the one hand, Experiment is a larger platform than Consano with 20 project categories, a few of them being related to medical research. Due to the larger pool of project categories and projects, higher number of potential donors visit the website. Potential donors might spill over from those other categories into the category of medical research. On the other hand, total funding per successful project, on average, is smaller on Experiment than on Consano (USD 10,229 vs USD 15,625), 
which makes it easier to raise the target sum (Consano, 2017b, Experiment 2017b). In case of Experiment, the fundraisers do not get the pledged funds until the target is met; a rule which motivates fundraisers to set realistic financial goals.

The variable of fundraising goal is significant at 5\% with a negative beta coefficient; the success rate of the campaign is marginally smaller, if the target sum is higher. This finding is in line with Mollick (2014) and Petitjean (2018), who arrived at the same conclusion by analysing 48,526 US-based campaigns listed on Kickstarter and 160 campaigns launched on the French KissKissBankBank platform, respectively.

The variable of innovation is significant at $5 \%$ with a negative beta coefficient; the more innovative the project is, the lower the probability of raising the target sum. Donors are risk averse, they disprefer projects where researchers employ an innovative approach that has never been used previously to cure the disease or was used in a very different context.

When comparing the actual donation behaviour documented in this research with the stated preferences of potential donors as reported by Dragojlovic and Lynd (2016), we find empirical evidence of inconsistency between stated and revealed preferences in crowdfunding. Dragojlovic and Lynd (2016) report that potential donors were comparatively more inclined to support campaigns that aim to treat diseases with early age of onset (pediatric diseases and diseases where patients acquire the symptoms in young adulthood and early middle age). Potential donors also showed strong preference for supporting projects which are more frequent. Moreover, potential backers were likely to provide donations for projects where the proposed treatment most likely cures the disease and patients do not have to live with the symptoms anymore. Potential donors were comparatively also more likely to support nonprofit organizations, projects where the university of the lead researcher had an excellent reputation, and where other funding was available. Potential donors also stated to prioritize projects, albeit to a lesser extent, where the impact on the quality of life of patients is severe and the mortality is high. In this research, none of these attributes were useful in predicting the success rate of crowdfunding campaigns. Stated charitable attitudes and behaviour thus cannot be used to forecast actual donation behaviour in crowdfunding medical research.

Several factors might explain why stated and revealed preferences differ and why disease characteristics are irrelevant in crowdfunding medical research. First, donors might be part of the fundraisers' personal or professional network and provide financial support to the scientists they know without considering the disease characteristics. This argument is supported by the estimate of Perlstein (2013), who reported that in their pharmacological campaign he was connected to $60 \%$ of the donors through social media. Second, donors might have friends or relatives who suffer from the disease and they are eager to provide financial support with the hope of easing the burden of their loved ones. Third, donors might be biased towards crowdfunding campaigns launched by recognized and prestigious universities or influential and highly respected scientists. Fourth, donors' actual funding behaviour may deviate from the planned one due to herding bias. If numerous people share information about a crowdfunding campaign on social networks, for example via tweets, donors might follow the consensus and end up funding that campaign.

Crowdfunding medical research is becoming more and more popular; it serves as an additional tool for financing research initiatives. The revealed preferences documented in this research might help scientists to pursue a successful crowdfunding campaign. Our findings highlight the importance of establishing and maintaining professional contacts through social media; an additional tweet or retweet increases the success rate of crowdfunding campaign by one 
percentage point. Nardi, Whittaker and Schwarz (2002) list three main tasks for keeping a successful professional network: building a network, maintaining the network and activating selected contacts. Tweeting is a tool for activating members in the personal and professional networks; scientists shall put effort in establishing and keeping up-to-date their networks beforehand.

Our results suggest that researchers should select the platform on which they plan to run their crowdfunding campaign carefully. Platforms with wider publicity are to be preferred over specialized, smaller platforms; the pool of potential donors is larger and thus the possibility of achieving the fundraising target is higher. More popular platforms might pay off, even if they are profit-oriented and charge a fee. At the same time, researchers should not set unrealistic funding goals as they might discourage donors from providing financial support.

Researchers may ask funding for any kind of project, including therapies for rare diseases and disorders where the first symptoms appear at later age of onset. Our results suggest that crowdfunding campaigns might reach their fundraising goal regardless of the disease characteristics such as disease frequency and age of onset. This finding matches the concern listed by Del Salvio (2017). As argued by the author, in crowdfunding, financial resource allocation is based on the judgement of donors not being experts in medical sciences. As a result, the public fails to allocate resources efficiently and prioritize research delivering the highest total value to the society. Nevertheless, it might be easier to build and engage an audience where the disease characteristics overlap with the stated preferences of the potential donors. Stated preferences reflect the attributes that donors and generally the wider public care about: diseases with high mortality rate, diseases with early age of onset, frequent diseases, and diseases causing severe pain and discomfort. Stated preferences are generally in line with the principles of resource allocation in healthcare: resources should be allocated where the largest total improvement is expected, that is, more people are affected, the quantity of life lived significantly increases, and the quality of life substantially improves. The total improvement is typically measured by the quality adjusted life year covering both the quality and the quantity of life lived; it is a widely used measure to assess the value for money of various interventions in healthcare, including funding (Angelis, Kanavos \& Montibeller, 2017; Brazier, Deverill \& Gree, 1999; Wouters, Naci \& Samani, 2015).

This research has several limitations. First, we focused on platforms which cover a variety of diseases; the success factors on platforms specialized on a single disease might slightly differ. Second, the number of observations is small (109 campaigns), while the number of independent variables is high (30 predictors). Austin and Steyerberg (2015), however, argue that linear regressions require only two subject per variable for estimating the regression coefficients, standard errors, and confidence intervals adequately (i.e., with a relative bias of less than 10\%). Third, we disregard when the information became available to the potential backers. Although the number of comments, tweets and updates evolve over time, in the model the values observed at the end of the campaign are included. Fourth, information about disease frequency, age of onset and mortality were obtained from scientific journals. Although two researchers independently determined the value of these variables, the estimate might be biased.

\section{Conclusions}

As government funded research grants for medical research are scant and have become increasingly competitive, scientists are prompted to search for alternative financing options. 
Crowdfunding might be regarded as a feasible option for funding medical research. Crowdfunding has the potential to complement but not to replace existing government funding. Central funding agencies should keep on fostering fundamental discoveries, innovative research approaches and their application as a basis for improving the health and wealth of the nations. These funding agencies should continue assuring efficient allocation of resources, and prioritize research which delivers the highest total value to the society, considering both the quality and the quantity of life lived, summed up across all individuals. As shown in this study, crowdfunding in medical research disregards the disease characteristics and the total value delivered to the society. In crowdfunding, scientists with large social networks, either personal or professional, are more likely to achieve their fundraising goal. Scientists who managed to develop good networking skills and/or their research became widely covered in the media have higher chances to succeed. From this respect crowdfunding imposes a negative externality on the society; campaigns are not evaluated on their merit they deliver to the society as a whole. This negative externality is nevertheless outweighed by the positive externality crowdfunding in medical research delivers to the society. Through crowdfunding additional financial resources are channelled into the system and more medical research projects are carried out in total.

\section{References}

Angelis, A., Kanavos, P., \& Montibeller, G. (2017). Resource Allocation and Priority Setting in Health Care: A Multi-criteria Decision Analysis Problem of Value? Global Policy, 8, 76-83.

Austin, P. C., \& Steyerberg, E. W. (2015). The number of subjects per variable required in linear regression analyses. Journal of Clinical Epidemiology, 68(6), 627-636.

Berliner, L. S., \& Kenworthy, N. J. (2017). Producing a worthy illness: Personal crowdfunding amidst financial crisis. Social Science \& Medicine, 187, 233-242.

Beshears, J., Choi, J. J., Laibson, D., \& Madrian, B. C. (2008). How are preferences revealed? Journal of Public Economics, 92(8-9), 1787-1794.

Brazier, J., Deverill, M. and Green, C. (1999). A Review of the Use of Health Status Measures in Economic Evaluation. Journal of Health Services Research \& Policy, 4 (3), pp. 174-184.

Brooks, K., \& Lusk, J. L. (2010). Stated and revealed preferences for organic and cloned milk: combining choice experiment and scanner data. American Journal of Agricultural Economics, 92(4), 1229-1241.

Brownstone, D., Bunch, D. S., \& Train, K. (2000). Joint mixed logit models of stated and revealed preferences for alternative-fuel vehicles. Transportation Research Part B: Methodological, 34(5), $315-$ 338.

Byrnes, J. E., Ranganathan, J., Walker, B. L., \& Faulkes, Z. (2014). To Crowdfund Research, Scientists Must Build an Audience for Their Work. PloS One, 9(12), e110329.

Cadogan, D. (2014). Funding for research? Look to the crowd: crowdfunding resources for academia. College \& Research Libraries News, 75(5), 268-271. 
Centres for Medicare and Medicaid Services (2018). National Health Expenditures 2017 Highlight. Retrieved 1 December 2018, https://www.cms.gov/Research-Statistics-Data-and-Systems/StatisticsTrends-and-Reports/NationalHealthExpendData/downloads/highlights.pdf

Consano (2017a). Consano Frequently Asked Questions. Retrieved 15 December 2017, https://consano.org/about/faq/

Consano (2017b). Consano Projects. Retrieved 15 December 2017, https://consano.org/donate/projects/

Dahlhausen, K., Krebs, B. L., Watters, J. V., \& Ganz, H. H. (2016). Crowdfunding campaigns help researchers launch projects and generate outreach. Journal of Microbiology \& Biology Education, $17(1), 32$

Del Savio, L. (2017). The Place of Crowdfunding in the Discovery of Scientific and Social Value of Medical Research. Bioethics, 31(5), 384-392.

Dragojlovic, N., \& Lynd, L. D. (2014). Crowdfunding drug development: the state of play in oncology and rare diseases. Drug Discovery Today, 19(11), 1775-1780.

Dragojlovic, N., \& Lynd, L. D. (2016). What will the crowd fund? Preferences of prospective donors for drug development fundraising campaigns. Drug Discovery Today, 21(12), 1863-1868.

Experiment. (2017a). Experiment Frequently Asked Questions. Retrieved December 15, 2017 from https://experiment.com/faq

Experiment. (2017b). Experiment Community Statistics. Retrieved December 15, 2017 from https://experiment.com/stats

Fumagalli, D. C., \& Gouw, A. M. (2015). Focus: Personalized Medicine: Crowdfunding for Personalized Medicine Research. The Yale Journal of Biology and Medicine, 88(4), 413.

Hughes, V. (2012). Strapped for funding, medical researchers pitch to the crowd. Nature Medicine, 18(1307).

Hui, J. S., Gerber, E. M., \& Gergle, D. (2014). Understanding and leveraging social networks for crowdfunding: opportunities and challenges. Proceedings of the 2014 Conference on Designing interactive systems (pp. 677-680). ACM.

Kuehn, B. M. (2014). Budget woes, sequester place researchers in a bind: young researchers hard hit. JAMA, 311(1), 15-16.

Lambooij, M. S., Harmsen, I. A., Veldwijk, J., de Melker, H., Mollema, L., van Weert, Y. W., \& de Wit, G. A. (2015). Consistency between stated and revealed preferences: a discrete choice experiment and a behavioural experiment on vaccination behaviour compared. BMC Medical Research Methodology, 15(1), 19.

Makris, G. C. (2015). Crowdfunding: from startup businesses to startup science. BMJ: British Medical Journal, 350:h18.

Mollick, E. (2014). The dynamics of crowdfunding: An exploratory study. Journal of Business Venturing, 29(1), 1-16.

Montgomery, D. C., Peck, E. A., \& Vining, G. G. (2012). Introduction to linear regression analysis (Vol. 821). John Wiley \& Sons. Hoboken, New Jersey. 
Moy, N., Chan, H. F., \& Torgler, B. (2018). How much is too much? The effects of information quantity on crowdfunding performance. PloS One, 13(3), e0192012.

Murphy, K. M., \& Topel, R. H. (2006). The Value of Health and Longevity. Journal of Political Economy, 114(5), 871-904.

Nardi, B. A., Whittaker, S., \& Schwarz, H. (2002). NetWORKers and their activity in intensional networks. Computer Supported Cooperative Work (CSCW), 11(1-2), 205-242.

National Institutes of Health. (2018a). NIH Budget History. NIH budget mechanism detail FY 2001 2017. Retrieved 8 November 2018,

https://report.nih.gov/NIHDatabook/Charts/Default.aspx?showm=Y\&chartId=153\&catId=1

National Institutes of Health. (2018b). Research grants: Competing applications and awards.

Retrieved September 10, 2018, from

https://report.nih.gov/nihdatabook/charts/Default.aspx?chartId=159\&catId=2

Perlstein, E. O. (2013). Anatomy of the Crowd4Discovery crowdfunding campaign. SpringerPlus, 2(1), 560 .

Petitjean, M. (2018). What explains the success of reward-based crowdfunding campaigns as they unfold? Evidence from the French crowdfunding platform KissKissBankBank. Finance Research Letters, 26(9), 9-14.

Schafer, J. L., \& Graham, J. W. (2002). Missing data: our view of the state of the art. Psychological Methods, 7(2), 147.

Vachelard, J., Gambarra-Soares, T., Augustini, G., Riul, P., \& Maracaja-Coutinho, V. (2016). A guide to scientific crowdfunding. PLoS Biology, 14(2).

Wouters, O. J., Naci, H. and Samani, N. J. (2015). QALYs in Cost-effectiveness Analysis: An Overview for Cardiologists. Heart, 101 (23), pp. 1868-1873.

Xu, A., Yang, X., Rao, H., Fu, W. T., Huang, S. W., \& Bailey, B. P. (2014). Show me the money! An analysis of project updates during crowdfunding campaigns. Proceedings of the SIGCHI Conference on Human Factors in Computing Systems, 591-600. 
Appendix, Table A1: Descriptive statistics of variables in model $2(\mathrm{~N}=109)$

\begin{tabular}{|c|c|c|c|c|}
\hline Variable & Mean & Std. Dev. & Min & Max \\
\hline \multicolumn{5}{|l|}{ Panel A: Disease characteristics } \\
\hline human/animal (1 human; 0 animal) & 0.89 & 0.31 & 0.00 & 1 \\
\hline- age 5 & 0.03 & 0.16 & 0.00 & 1 \\
\hline age $5-$ age 40 & 0.28 & 0.45 & 0.00 & 1 \\
\hline age $40-$ age 50 & 0.05 & 0.21 & 0.00 & 1 \\
\hline age $50-$ age 70 & 0.64 & 0.48 & 0.00 & 1 \\
\hline -freq 1 in 15 & 0.01 & 0.10 & 0.00 & 1 \\
\hline freq 1 in $15-1$ in 50 & 0.03 & 0.16 & 0.00 & 1 \\
\hline freq 1 in $50-1$ in 1,000 & 0.62 & 0.49 & 0.00 & 1 \\
\hline freq 1 in $1,000-1$ in 100,000 & 0.31 & 0.47 & 0.00 & 1 \\
\hline freq 1 in $100,000-$ & 0.03 & 0.16 & 0.00 & 1 \\
\hline quality ( 1 severe; 0 moderate) & 0.72 & 0.45 & 0.00 & 1 \\
\hline treat_low & 0.26 & 0.44 & 0.00 & 1 \\
\hline treat_medium & 0.56 & 0.50 & 0.00 & 1 \\
\hline treat_high & 0.18 & 0.39 & 0.00 & 1 \\
\hline mortality $0-5 \%$ (10 years) & 0.06 & 0.25 & 0.00 & 1 \\
\hline mortality $5 \%-40 \%$ (10 years) & 0.12 & 0.33 & 0.00 & 1 \\
\hline mortality $40 \%-80 \%$ (10 years) & 0.72 & 0.45 & 0.00 & 1 \\
\hline mortality $80 \%-100 \%$ (10 years) & 0.09 & 0.29 & 0.00 & 1 \\
\hline \multicolumn{5}{|c|}{ Panel B: Medical research characteristics } \\
\hline cure (1 cure; 0 research) & 0.35 & 0.48 & 0.00 & 1 \\
\hline innovation (1 high; 0 low) & 0.72 & 0.45 & 0.00 & 1 \\
\hline effectiveness ( 1 cure; 0 benefit) & 0.94 & 0.25 & 0.00 & 1 \\
\hline devel_st_early & 0.78 & 0.42 & 0.00 & 1 \\
\hline devel_st_mid & 0.21 & 0.41 & 0.00 & 1 \\
\hline devel_st_late & 0.01 & 0.10 & 0.00 & 1 \\
\hline- goal $40 k$ & 0.94 & 0.23 & 0.00 & 1 \\
\hline goal $40 k-300 k$ & 0.05 & 0.21 & 0.00 & 1 \\
\hline goal 300k - goal $1 m$ & 0.01 & 0.10 & 0.00 & 1 \\
\hline \multicolumn{5}{|c|}{ Panel C: Organizational characteristics } \\
\hline org (1 for-profit; 0 non-profit) & 0.06 & 0.25 & 0.00 & 1 \\
\hline phd (number of researchers) & 0.72 & 1.02 & 0.00 & 5 \\
\hline additional fund ( 1 yes; 0 no) & 0.28 & 0.45 & 0.00 & 1 \\
\hline \multicolumn{5}{|l|}{$\begin{array}{l}\text { Panel D: Communication and } \\
\text { design }\end{array}$} \\
\hline twit & 28.27 & 206.64 & 0.00 & 2,155 \\
\hline twit winsorized & 9.38 & 22.30 & 0.00 & 115 \\
\hline comments & 16.84 & 36.81 & 0.00 & 303 \\
\hline comments winsorized & 15.26 & 26.67 & 0.00 & 139 \\
\hline photo & 0.77 & 0.42 & 0.00 & 1 \\
\hline video & 0.64 & 0.48 & 0.00 & 1 \\
\hline updates & 3.78 & 5.65 & 0.00 & 28 \\
\hline interim results & 0.28 & 0.45 & 0.00 & 1 \\
\hline length & 900.92 & 323.20 & 427.00 & 1,706 \\
\hline platform (1 Experiment; 0 Consano) & 0.74 & 0.44 & 0.00 & 1 \\
\hline
\end{tabular}

Variables highlighted in grey denote the categorical variables used in the second model. For the four variables with outliers, figures in italics show the descriptive statistics after winsorization. 
Table A2: OLS regression results of model 2

\begin{tabular}{lrcc}
\hline Variables & coefficients & p-value & 95\% CI \\
\hline Disease characteristics & & & \\
\hline human/animal & 1.48 & 0.72 & {$[-22.27-32.05]$} \\
- age 5 & 2.63 & 0.64 & {$[-56.3-91.67]$} \\
age 5 - age 40 & 10.91 & 0.42 & {$[-101.19-42.64]$} \\
age 40 - age 50 & -30.71 & 0.98 & {$[-64.71-62.91]$} \\
freq 1 in 15 - 1 in 50 & 2.21 & 0.91 & {$[-35.95-40.37]$} \\
freq 1 in 50 - 1 in 1,000 & 7.82 & 0.47 & {$[-13.52-29.16]$} \\
freq 1 in 100,000 - & -24.65 & 0.42 & {$[-85.39-36.09]$} \\
quality & 26.57 & 0.17 & {$[-10.3-59.51]$} \\
treat_low & 24.41 & 0.08 & {$[-3.13-53.11]$} \\
treat_high & 26.78 & 0.29 & {$[-17.58-58.28]$} \\
mortality 0-5\% (10 years) & -22.07 & 0.33 & {$[-67.01-22.87]$} \\
mortality 5\%-40\% (10 years) & -10.29 & 0.50 & {$[-40.15-19.57]$} \\
mortality 80\%-100\% (10 years) & 1.14 & 0.95 & {$[-36.86-39.14]$} \\
\hline Medical research characteristics & & & \\
\hline cure & 2.42 & 0.81 & {$[-17.26-22.11]$} \\
innovation & -15.94 & 0.11 & {$[-35.66-3.77]$} \\
effectiveness & 12.54 & 0.39 & {$[-16.14-41.23]$} \\
devel_st_mid & 16.80 & 0.27 & {$[-13.54-47.15]$} \\
devel_st_late & -17.86 & 0.37 & {$[-57.47-21.75]$} \\
goal 40k - 300k & -36.18 & 0.18 & {$[-89.9-17.53]$} \\
\hline Organizational characteristics & & & \\
\hline org & -25.70 & 0.31 & {$[-75.9-24.5]$} \\
phd & 5.43 & 0.33 & {$[-5.69-16.56]$} \\
additional fund & -0.39 & 0.97 & {$[-23.55-22.78]$} \\
\hline Communication and design & & & \\
\hline length & -0.01 & 0.46 & {$[-0.03-0.01]$} \\
comments winsorized & -0.54 & 0.06 & {$[-1.09-0.02]$} \\
twit winsorized & $\mathbf{1 . 7 2 * * *}$ & $\mathbf{0 . 0 0}$ & {$[\mathbf{0 . 7 7 - 2 . 6 8}]$} \\
photo & -11.58 & 0.29 & {$[-33.36-10.2]$} \\
video & 4.43 & 0.67 & {$[-16.17-25.04]$} \\
updates & 1.23 & 0.23 & {$[-0.79-3.25]$} \\
results & $\mathbf{4 8 . 8 0 * * *}$ & $\mathbf{0 . 0 0}$ & {$[\mathbf{2 0 . 9 1 - 7 6 . 6 8 ]}$} \\
\hline & & & \\
\hline
\end{tabular}

$* \mathrm{p}<0.05 . * * \mathrm{p}<0.01, * * * \mathrm{p}<0.001$

Variables highlighted in grey denote the categorical variables used in the second model. Coefficients that are significant at least at the 5\% level are highlighted in bold. The R-squared of the model is 0.5850 , while the adjusted R-squared is 0.4254 . For categorical variables the table excludes the reference category. As a result of winsorization, two categories have zero observations (disease being more frequent than 1 in 15; fundraising goal 300k - goal $1 \mathrm{~m}$ ); these categories are not shown in the table. 